\title{
Psychosocial repercussions experienced by parents who care for infants with syndromic orofacial clefts
}

Rayanne Meyer Barduzzi 1

iD https://orcid.org/0000-0002-3626-6025

Ana Paula Ribeiro Razera 2

iD https://orcid.org/0000-0002-5462-3962

Francely Tineli Farinha 3

(iD https://orcid.org/0000-0002-1982-5024

Gesiane Cristina Bom 4

iD https://orcid.org/0000-0003-1091-1767

Maila Meryellen Ferreira Garcia Manso 5

iD https://orcid.org/0000-0001-7298-5353
Armando dos Santos Trettene 6

iD https://orcid.org/0000-0002-9772-857X

\footnotetext{
1,3,4,5 Programa de Pós-graduação em Ciências da Reabilitação. Hospital de Reabilitação de Anomalias Craniofaciais. Universidade de São Paulo. Rua Silvio Marchione, 320. Vila Nova Cidade Universitária. Bauru, SP, Brasil. CEP: 17012-900. E-mail: armandotrettene@usp.br
}

2 Departamento de Enfermagem. Instituto de Ciências da Saúde. Universidade Paulista. Bauru, SP, Brasil.

\begin{abstract}
Objectives: to understand the psychosocial implications experienced by caregiving parents, resulting from the care of the child with cleft lip and/or palate associated with the syndrome.

Methods: a cross-sectional and qualitative study, guided by the Consolidated Criteria for Reporting Qualitative Research tool, carried out between January and May 2019. Data collection was carried out through semi-structured interviews that were audio-recorded and transcribed in full. Thematic content analysis was used as the methodological framework and Symbolic Interactionism as the theoretical framework.

Results: the participants were 16 caregiving parents. Four categories were listed: implications for diagnosis and treatment initiation, implications for financial issues and paid activities, implications for the care process, and implications for access to health resources.

Conclusion: it was found that psychosocial implications experienced by these informal caregivers are multifaceted and complex, and that knowing them will enable planning and implementation of actions that contribute, in addition to the children's rehabilitation process, to the health and quality of life of those who care.

Key words Cleft lip, Cleft palate, Caregivers, Psychosocial support systems, Psychosocial impact
\end{abstract}

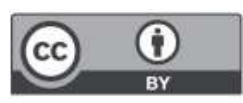




\section{Introduction}

Cleft lip and/or palate is a public health demand, as it prevails among the malformations that affect the face. In Brazil, its incidence is 1/750 live births. Its etiology is multifactorial and includes environmental and genetic factors, with the possibility of manifesting in isolation or associated with other syndromes. 1

Among the syndromes associated with cleft lip and/or palate, there is prevalence of the Robin, Stickler, Treacher Collins and Van der Woude sequences. These children frequently need respiratory and/or food support, including nasopharyngeal tubes, tracheostomy, feeding tubes, gastrostomy and postural anti-reflux treatment, among others. ${ }^{2}$ However, in most cases, the use of these therapies does not contraindicate hospital discharge, as long as parents or informal caregivers are trained to maintain care at home. 3

Thus, in view of the new care demand, these caregivers experience significant changes in their lives, having to adapt to the new reality imposed on them. In this sense, it is frequently the parents that assume that responsibility, acting as informal caregivers. 4,5

These caregiving parents, in addition to facing the difficulties related to the process of caring for the infant, will have to deal with conflicting and stressful feelings and situations, which are present from the moment of diagnosis of their children and may extend into childhood, adolescence or adulthood. 6

In short, the process of caregiving is an arduous task, which can overburden the caregiver, in addition to physical, psychological, emotional, social and financial disorders, with the need for family reorganization.?

Given the above, it was sought to answer the following question: Which are the psychosocial implications experienced by parents who are informal caregivers of infants with cleft lip and/or palate associated with some syndrome?

Although studies on the care of infants with cleft lip and/or palate associated with the syndrome are available, ${ }^{3-6}$ those referring to the universe of social implications experienced by caregiving parents are incipient.

Thus, the objective was to understand the psychosocial implications experienced by caregiving parents resulting from the care of a child with cleft lip and/or palate associated with syndromes since, through this situational diagnosis, it will be possible to plan and implement actions targeted at those who care, aiming at promoting and maintaining their health.

\section{Methods}

A descriptive and cross-sectional study with a qualitative approach, developed in a public and mediumsized tertiary-level hospital, a reference in the care of patients with craniofacial anomalies and related syndromes, located in the inland of São Paulo, Brazil.

The hospital unit included in this study was the Semi-Intensive Care unit, consisting of eight beds for the care of newborns to children up to two years old, who have respiratory and food demands. In addition to that, in this unit, informal caregivers remain during the children's hospitalization to receive training regarding care, with a view to maintaining them at home after hospital discharge.

The intentional and convenience sample was defined by theoretical saturation, that is, data collection was concluded when no new information was obtained from the speeches, showing that understanding of the phenomenon studied was achieved. 8 This process took place in the $16^{\text {th }}$ interview, that is, 16 informal caregivers.

The inclusion criteria were as follows: being a father/mother or responsible informal caregiver of infants hospitalized in the semi-intensive unit in the data collection period, who were not in the first hospitalization, configuring home care.

As a theoretical framework, Symbolic Interactionism was used, where the definition of the situation experienced is central to direct the actions, as they are caused by an active decision-making process of the individual, in addition to interaction, with oneself and with others. It comprises five central ideas, including the following: the role of social interaction, thought, definition, the present and the active human being, where action occurs from the establishment of attributed meanings. Thus, while individuals interact, their current experience influences their actions. In other words, any phenomenon needs to be apprehended and understood from the perspective of the person who experiences it. 9

As a methodological framework, Thematic Content Analysis was used, which, according to Bardin8 "consists of a discourse analysis technique aiming to understand it, subtracting themes, categories and subcategories, that is, the possibility of discovering the nuclei of meaning that make up communication".

A semi-structured interview with the following 
questions was used for data collection: How has it been for you to care for your child? Which were the main changes in your daily activities after you started caring for your child? Which are the greatest difficulties you find in caring for your child? Do you feel supported? Were you able to access the community resources for treatment maintenance and continuity?

The interviews took place in a private environment, during hospitalization of the infants, at a time that is relevant for the parents, and were recorded on a digital audio device. After each interview, the content of the recordings was transcribed in full, aiming to facilitate the analysis process of the emerging data.

The mean duration of the interviews was 40 minutes. Data analysis was performed concomitantly with the interviews, aiming at identifying when the speeches started to show recurrence. The participants were also characterized according to age, gender, marital status, number of children, socioeconomic classification 10 and schooling.

Data collection took place between January and May 2019. To prepare the study, the Consolidated Criteria for Reporting Qualitative Research (COREQ) guideline in its Portuguese translated version was used. 11

Treatment of the results was carried out through the inference and interpretation of the contents by categories and similarity, following the Thematic Content Analysis methodology, systematized in the following phases: pre-analysis - through skim reading of the interview contents by means of the principles of exhaustiveness, representativeness, homogeneity and relevance; exploration of the material - where coding operations are constructed through the identification of keywords and related themes, with subsequent aggregation of information into thematic categories; interpretation - treatment of the results, inference and interpretation, supported by the theoretical framework of Symbolic Interactionism. 8,9

The research was initiated after approval of the Hospital's Research Ethics Committee by means of Edict No. 3,112,342 and CAAE: 04319418.0.0000.5441. To identify the speeches and ensure anonymity, the letter "C" meaning Caregiver was used for each participant, as well sequential Arabic numbers.

\section{Results}

The study participants were 16 informal caregivers: 14 mothers and 2 maternal grandmothers. Among them, there was prevalence of those who had completed high school, married, with a mean age of 31 years old, with two children, belonging to a low socioeconomic classification 10 and unemployed.

Based on content analysis, four categories referring to the psychosocial repercussions related to the care process were listed, namely: (1) implications regarding diagnosis and treatment initiation, (2) implications related to financial issues and paid activities, (3) implications related to the care process with the following subcategories: stress and burden, protagonism, relationship with the nuclear family and support network, and (4) implications regarding access to health resources.

\section{1) Implications regarding diagnosis and treatment initiation}

It was characterized by lack of access to the information and by a wide range of negative feelings, including fright, insecurity, fear and concern.

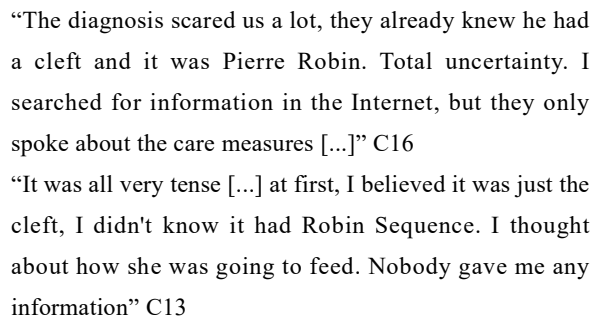

\section{2) Implications related to the financial issues and to those of paid activities}

Due to the demands of the infant's care, the caregivers reported the need to leave work or to be absent frequently due to hospital readmissions.

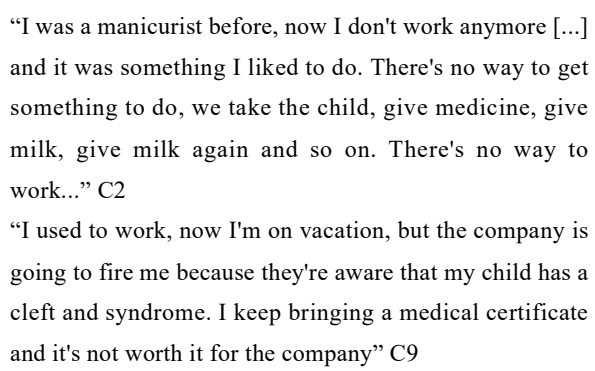

\section{3) Implications related to the care process}

This category encompassed four categories, namely: stress and overload, leading role, relationships with the family nucleus, and support network.

It was discovered that the high stress and overload level experienced was related to the burden imposed by the care process, in addition to taking care of the house, the other children and the spouse. 
For these reasons, relationships in the family nucleus became conflicting, and the leading role played by the mother fostered emotional strain. On the other hand, when they felt supported, the negative feelings were minimized.

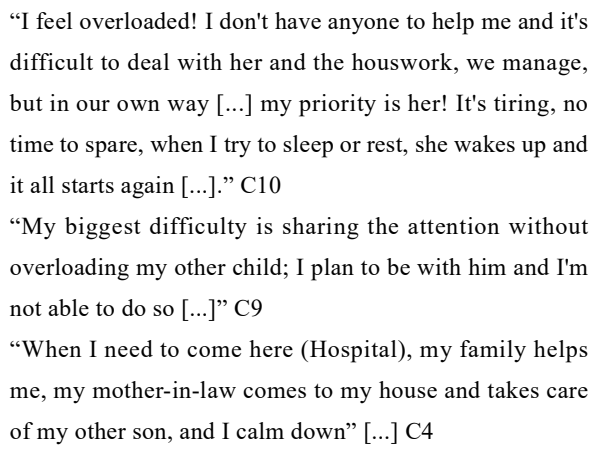

\section{4) Implications referring to access to the health services}

In this category, issues called facilitators and barriers to access were apprehended. Among the facilitators, there was access to specialized treatment and the team's humanized perspective.

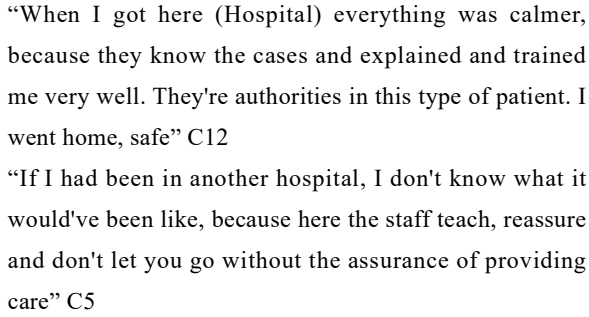

On the other hand, the barriers to access were related to the unavailability of allowances for simple or specialized transportation, depending on the child's clinical condition.

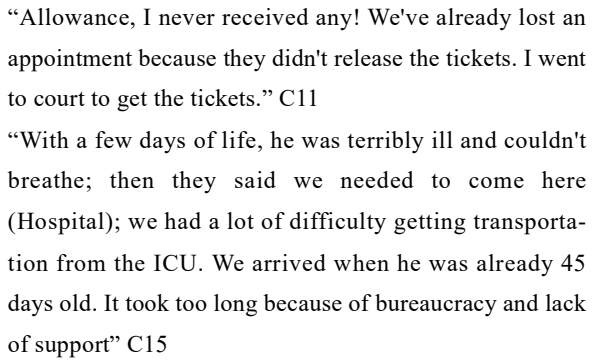

In addition, difficulties were revealed regarding acquisition of specific inputs and materials.

"I got the milk and the materials, but with great difficulty

$[\ldots]$ we have to struggle to get the materials [...] the tube is the most difficult, and we often have to buy it." C3

"So far they haven't given me anything, and since they haven't, I bought it, because I can't leave the baby unfed; the vacuum tubes they provided some and said we had to wait for them to arrive; I can't stop vacuuming, so I have to find a way and buy $[\ldots] " \mathrm{C} 7$

\section{Discussion}

Diagnosis of cleft lip and/or palate and of the syndrome is a stressful factor, as parents are concerned about the unexpected results of the foreseen transitions in the life cycle, which increases pressure on the family system and influences adaptability to the new situation.12-14 However, the family experiences moments of restlessness for not knowing the specific care that the child will need. 15

In this sense, guidance by qualified professionals as early as possible, as well as training of the caregiving parents during the child's hospitalization, has proved to be promising. 3,16

In fact, acquisition of knowledge about the demands of care and treatment is configured as a priority need, as it will influence the quality of care provided.17,18 Furthermore, the health team is expected to teach coping skills and psychosocial support. 19

In this research, it was unveiled that the mother figure emerged as the protagonist regarding the caregiver role, a fact that can be related to historical and cultural contexts where the care of children is linked to motherhood, or due to feelings of concern or guilt that manifest through lack of trust in other people. In addition to that, routinely, the other family members do not consider themselves capable of developing this function. $5,13,18,20$

The mother, as the main caregiver, in addition to providing childcare, is responsible for managing the home, caring for other children, for her spouse and for herself. In association, these factors contribute to increased stress and burden, which, as far as they are concerned, will bring about devastating consequences, both physical and social.21,22 Thus, identifying them is the first step to plan psychoeducational and psychotherapeutic interventions, aiming to improve the support network and the situational coping ability of the caregivers. $4,5,17$

The caregiver's burden is the result of the need for physical, psychological and social care, causing an imbalance between these demands and other responsibilities, such as personal social duties, roles at work and in the family. 21

Therefore, many caregivers experience family and affective disorders, not being uncommon that the 
other children feel excluded or abandoned. In many cases, emotional distancing also occurs in the couple, culminating in frequent disagreements and even divorce. 5,23

In this study, the most influenced dimensions were family interactions, the feeling of a closer relationship in the family, the need for communication with the partner, and lack of adequate time for other family members and other children. A similar result was evidenced in a Brazilian study that included informal caregivers of children with dysphagic orofacial cleft, using a feeding tube. 5

It is emphasized that family relationships are fundamental to adequately face chronic diseases and the prolonged treatment that is often necessary in these conditions. Therefore, family monitoring is fundamental. 14,24

Among the impacts experienced by informal caregivers in the activities of daily living, the financial and social ones stood out, corroborating the results of other research studies. 16,24 This is a worrying fact, considering that the treatment of these children can demand significant costs, compromising the family's financial issue. 13 In this sense, the construction of support networks is indispensable, as is the access to social benefits guaranteed by law and community benefits. $23-25$

Financial difficulties are frequently referred to as an important obstacle to the rehabilitation process, which can be related to the need for the main caregiver to abandon their job to meet the demand for care that the child needs. 26,27

Added to this are the difficulties accessing health care, which in this study were related to transportation aid and to acquisition of supplies or materials. It was also found that the families suffered between comings and goings in institutions that did not accept their demands nor effectively referred them to the specialized service. Adequate access to treatment and information are essential in the rehabilitation process, in addition to providing comfort to the parents and improving the patient's quality of life. 28,29

Given this scenario, there is an evident need for educational and training programs for health professionals outside specialized centers, public awareness of orofacial clefts and related syndromes, in addition to social support programs. The rarer and more complex the disease, the more expert advice is needed. 16,28

Although there are laws and public policies in this area, their access and implementation are below the desired. Unfortunately, deficiencies in the health system, lack of public awareness about the malfor- mation, and insufficient social support services are realities in both the national and international scenario. $5,12,13$

However, it was perceived that access to specialized treatment and the humanized approach by the team proved to be facilitators of the rehabilitation process. In fact, being welcomed, as well as showing the quality of a service, results in trust and complicity. 28,29

In short, the premises of Symbolic Interactionism are reasserted, which discerns that human beings attribute a meaning based on their social relationships, that is, being supported by a professional suggests that the situation can be dealt with, being less complicated than it seems. ${ }^{9}$

Thus, it is necessary to implement and monitor family-centered care models to support not only the primary informal caregivers, but the entire family structure in caring for these children. 30

However, although this need is emerging, it is a challenge for health professionals, as they need preparation that allows them to transcend the merely technical care of the hospital context to a care practice that sees the family as a protagonist in promoting the quality of life of these children.

The fact that only a single interview may not have been sufficient to record the senses and meanings attributed by the participants is considered a limitation of this study. However, the benefits are evident, and include pointing out specific difficulties faced by informal caregiving, as well as areas for improvement regarding support, both for them and for the family. These findings reinforce the need for family-centered care models, in addition to the creation and strengthening of public policies that favor integrated care for those who provide care.

In the end, it was noticed how the psychosocial implications experienced by these caregivers are multifaceted and complex. Knowing them will make it feasible to plan and implement actions that contribute to, beyond the children's rehabilitative process, to the health and quality of life of those who care for them, for which monitoring and interventions should be the subject of further research studies.

\section{Authors' contribution}

Barduzzi RM: contributed in planning the study, participated in data collection, writing of the manuscript, analysis and discussion of the results. Razera APR: participated in discussion of the results in the critical review of the content. Farinha FT: participated in analysis and discussion of the results, 
review of the versions and critical review of the content. Bom GC: participated in data collection, analysis and discussion of the results. Manso MMFG: participated in data collection. Trettene AS: coordinated the research and planning of the study, writing of the manuscript, analysis and discussion of

\section{References}

1. Xiao Y, Taub MA, Ruczinski I, Begum F, Hetmanski JB, Schwender H, et al. Evidence for SNP-SNP interaction identified through targeted sequencing of cleft case-parent trios. Genet Epidemiol Sci. 2017; 41 (3): 244-50.

2. Salmen ICDM, Maques IL. In situ and home care nasopharyngeal intubation improves respiratory condition and prevents surgical procedures in early infancy of severe cases of Robin Sequence. Biomed Res Int. 2015; 2015 608905 .

3. Mondini CCSD, Fontes CMB, Trettene AS, Cianciarullo TI, Lazarini IM. Applicability of Orem: training of caregiver of infant with Robin Sequence. Rev Bras Enferm. 2018; 71 (Suppl.3): S1469-S73.

4. Razera APR, Trettene AS, Niquerito AV, Tabaquim MLM Study of burden among caregivers of children with cleft lip and palate. Paidéia (Ribeirão Preto). 2017; 27 (68): 3-10.

5. Banhara FL, Farinha FT, Bom CG, Razera APR, Tabaquim MLM, Trettene AS. Parental care for infants with feeding tube: psychosocial repercussions. Rev Bras Enferm. 2020; 73 (2): e20180360.

6. Nidey N, Uribe LMM, Marazita MM, Wehby GL. Psychosocial well-Being of parents of children with oral clefts. Child Care Health Dev. 2016; 42 (1): 42-50.

7. Carvalho A, Araújo LJP, Veríssimo MT. When long-term care comes to an end: informal caregivers' perspectives on patient discharge. Referência. 2019; 4 (22): 107-15.

8. Bardin L. Análise de conteúdo. São Paulo: Edições 70 , 2013.

9. Charon JM. Symbolic Interacionism: an introduction, an interpretation, as integration. 10 Ed. Boston: Prentice Hall; 2010.

10. Graciano MIG, Santiago MC, Bonfim EO, Galvão KA Aspectos sociofamiliares constitutivos do estudo social de adolescentes com fissura labiopalatina. Arq Ciênc Saúde. 2015; 22 (1): 79-84.

11. Souza VR, Marziale MH, Silva GT, Nascimento PL. Translation and validation into Brazilian Portuguese and assessment of the COREQ checklist. Acta Paul Enferm. 2021; 34: eAPE02631

12. Luquetti DV, Brajcich MR, Stock NM, Heike CL, Johns AL. Health care and psychosocial experiences of individuals with craniofacial microsomia: patient and caregivers perspectives. Int J Pediatr Otorhinolaryngol. 2018; 107: 164-75.

13. Hlongwa P, Rispel LC. "People look and ask lots of questions": caregivers' perceptions of healthcare provision and support for children born with cleft lip and palate. BMC Public Health. 2018; 18 (1): 506. the results, review of the versions and critical review of the content. All authors approved the final version of the article.

14. Viana ACG, Alves AMPM, Lopes MEL, Lima DRA, Batista PSS, Vasconcelos MF. Mães de bebê malformado: percepção sobre orientações de enfermeiro. J Nurs UFPE. 2019; 13: e239825.

15. Lima AGT, Sales CCS, Serafim WFL. Burden, depression and anxiety in primary caregivers of children and adolescents in renal replacement therapy. J Bras Nefrol. 2019; 41 (3): 356-63

16. Beluci ML, Mondini CCSD, Trettene AS, Dantas RAS. Correlation between quality of life and burden of family caregivers of infants with cleft lip and palate. Rev Esc Enferm USP. 2019; 53: e03432.

17. Fernandes CS, Angelo M. Family caregivers: what do they need? An integrative review. Rev Esc Enferm USP. 2016; 50 (4): $672-8$.

18. Awoyale T, Onajole AT, Ogunnowo BE, Adeyemo WL, Wanyonyi KL, Butali A. Quality of life of family caregivers of children with orofacial clefts in Nigeria: a mixed-method study. Oral Dis. 2016; 22 (2): 116-22

19. Boztepe H, Çınar S, Özgür FF. Parenting stress in turkish mothers of infants with cleft lip and/or palate. Cleft Palate Craniofac J. 2020; 57 (6): 753-61.

20. Muylaert CJ, Delfini PSS, Reis AOA. Relações de gênero entre familiares cuidadores de crianças e adolescentes de serviços de saúde mental. Physis. 2015; 25 (1): 2015.

21. Trettene AS, Turbiani ACA, Razera APR, Souza NFH, Turbiani DR, Silva JSG. Estresse e sobrecarga em cuidadores informais de crianças com Sequência de Robin Isolada. J Nurs UFPE. 2017; 11 (8): 3013-20.

22. Dunbar SB, Khanjou OA, Bakas T, Hunt G, Kirch RA, Leib AR, Morrison RS, Poehler DC, Roger VL, Whitsel LP. Projected costs of informal caregiving for cardiovascular disease: 2015 to 2035: A Policy Statement From the American Heart Association. Circulation. 2018; 137 (19): 558-77.

23. Macho P, Bohac M, Fedeles J Jr, Fekiacova D, Fedeles J Sr. Impact of cleft lip and/or palate in children on family quality of life before and after reconstructive surgery. Bratisl Med J. 2017; 118 (6): 370-3.

24. Emeka CI, Adeyemo WL, Ladeinde AL, Butali A. A comparative study of quality of life of families with children born with cleft lip and/or palate before and after surgical treatment. J Korean Assoc Oral Maxillofac Surg. 2017; 43 (4): 247-55.

25. Dantas KO, Neves RF, Ribeiro KSQS, Brito GEG, Batista $\mathrm{MC}$. Repercussions on the family from the birth and care of children with multiple disabilities: a qualitative metasynthesis. Cad Saúde Pública. 2019; 35 (6): e00157918. 
26. Simione M, Dartley AN, Cooper-Vince C, Martin V, Hartnick C, Taveras EM, Fiechtner L. Family-centered outcomes that matter most to parents: a pediatric feeding disorders qualitative study. J Pediatr Gastroenterol Nutr. 2020; 71 (2): 270-5.

27. Bossa PMA, Pacheco STA, Araújo BBM, Nunes MDR, Silva LF, Cardoso JMRM. Home care challenges facing families of children using a tracheostomy cannula. Rev Enferm UERJ. 2019; 27: e43335.

28. Bolla BA, Fulconi SN, Baltor MRR, Dupas G. Cuidado da criança com anomalia congênita: a experiência da família. Esc Anna Nery Rev Enferm. 2013; 17 (2): 284-90.
29. Kumar K, Kumar S, Mehrotra D, Gupta S, Khandpur S, Mishra RK. A psychologic assessment of the parents of patients with cleft lip and palate. J Craniofac Surg. 2020; 31 (1): 58-61.

30. Bom GC, Prado PC, Farinha FT, Manso MMFG, Dutka, Trettene AS. Stress, overload and quality of life in caregivers of children with/without orofacial cleft and dysphagia. Texto Contexto Enferm. 2021; 30: e20200165.

Received on November 5, 2020

Final version presented on August 19, 2021

Approved on September 20, 2021 